\title{
CRREL
}

(2)

A Comparison of Test Methods for Determination of Flexural Strength in Urea Model Ice

Sharon L. Borland

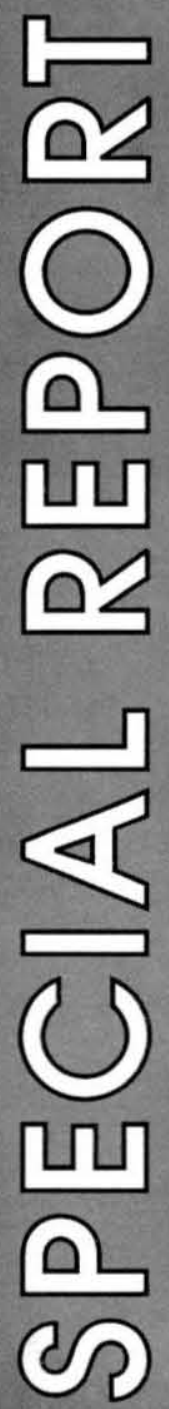


Special Report 90-28

\section{A Comparison of Test Methods for Determination of Flexural Strength in Urea Model Ice}

Sharon L. Borland 


\section{PREFACE}

This report was prepared by Sharon L. Borland, Research Hydraulic Engineer, Ice Engineering Research Branch, Experimental Engineering Division, U.S. Army Cold Regions Research and Engineering Laboratory. This work was funded by Civil Works CWIS 31723 under the work unit Model Studies and Ice Effects on Structures.

The author expresses great appreciation to Dr. Devinder Sodhi of CRREL for his valuable assistance in all phases of this experimental investigation, which included setting up the data acquisition system and instrumentation and providing the beam test apparatus. She thanks Carl Martinson for his assistance in conducting this experiment. She also thanks Dr. Sodhi and Dr. Jean-Claude Tatinclaux of CRREL for their advice and discussion and their technical reviews of this report.

The contents of this report are not to be used for advertising or promotional purposes. Citation of brand names does not constitute an official endorsement or approval of the use of such commercial products. 


\title{
A Comparison of Test Methods for Determination of Flexural Strength in Urea Model Ice
}

\author{
SHARON L. BORLAND
}

\section{INTRODUCTION}

Studies of forces and displacements resulting from the interaction of ice and structures commonly involve physical models. The accuracy of such models to simulate ice-structure interaction relies heavily on their ability to correctly model both geometry and mechanical properties. In many practical problems involving ice-structure interaction (e.g. artificial islands for petroleum exploration in the Arctic, conical-shaped light piers, ice-breaking ships), bending or flexure of the ice is an important failure mode. This makes the flexural strength $\sigma_{\mathrm{f}}$ one of the most significant properties of the modeling material. For example, in the CRREL test basin when urea-doped ice is used, the ice's flexural strength is monitored throughout the tempering period of an ice sheet (approximately 20 hours). Testing proceeds only when the desired value of $\sigma_{f}$ is reached. Because of the strong time dependency of $\sigma_{f}$ for urea ice, the method for measuring $\sigma_{\mathrm{f}}$ must be quick, accurate and efficient.

An in-situ cantilever beam test (CBI) method is currently used to determine the flexural strength of ice in the CRREL test basin. This test measures the load $P_{\max }$ necessary to break the beam. Flexural strength is then calculated using $P_{\max }$ and elastic beam theory. The CBI test, used extensively to measure $\sigma_{\mathrm{f}}$ for ice in the field as well as in the laboratory, is relatively simple to set up and perform, and it provides consistent results when done properly. This method, however, yields $\sigma_{\mathrm{f}}$ values that may be considered, at best, to be an index value of true flexural strength of the ice. The actual flexural strength can only be calculated by recognizing an ice beam as a nonhomogeneous, anisotropic, elasto-viscoplastic material. Unfortunately this is impossible with current analytical techniques. Good approximations of $\sigma_{f}$ can be made using elastic beam theory. Also, certain constraints in testing technique [as outlined in the recommendations of the IAHR Working Group on Ice Testing Methods (Schwarz et al. 1981)] must be followed.
Another method used to determine $\sigma_{\mathrm{f}}$ is the simple beam test with three-point loading (SB). This test can be conducted in situ (SBI) or out of the water (SBO). Problems with beam root deformations due to plate effects and stress concentrations in CBI tests can be minimized with SB tests (Svec and Frederking 1981). Furthermore, in at least one case [tests on urea ice in the NRCC ice model tank (Timco 1985)], results from SB tests have been found to be the same as those from CBI tests. Since the SB test may be more reliable for determining $\sigma_{\mathrm{f}}$, I performed a series of experiments to compare $\sigma_{f}$ obtained with CBI, SBI and SBO test methods. These tests were conducted on urea ice in the CRREL test basin. Specifically the following objectives were defined: 1) determine the flexural strength of urea ice using the two beam methods, 2) compare the threepoint simple beam method for both in-situ and out-ofwater conditions, and 3) compare $\sigma_{f}$ and its variation with respect to beam geometry.

\section{EXPERIMENTAL PROCEDURE}

\section{Ice sheet growth and description}

The urea ice sheets used to produce the beam samples in this study were grown from an aqueous solution of $0.95 \%$ urea by weight. To assure uniform distribution of thickness and mechanical properties throughout each ice sheet, the following techniques were used to produce each ice sheet tested. The solution was initially mixed using air bubblers and circulating pumps and then cooled by heat exchange at the air/water interface until the solution reached a uniform temperature of $-0.1{ }^{\circ} \mathrm{C}$. The bubblers and pumps were then shut off, and the solution was "wet seeded" by spraying a fine mist of water into the cold $\left(-12^{\circ} \mathrm{C}\right)$ air above the water surface. The resulting ice crystals settled on the water surface and nucleated the ice sheet. The ice sheet was grown at an ambient air temperature of $-18^{\circ} \mathrm{C}$ until a target thickness was achieved. At this time the air temperature was raised to 

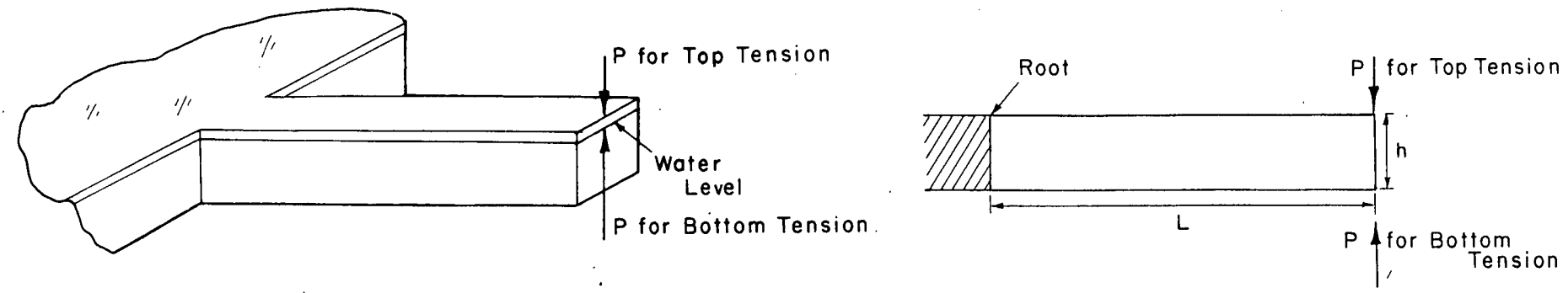

a. In-situ cantilever beam test.
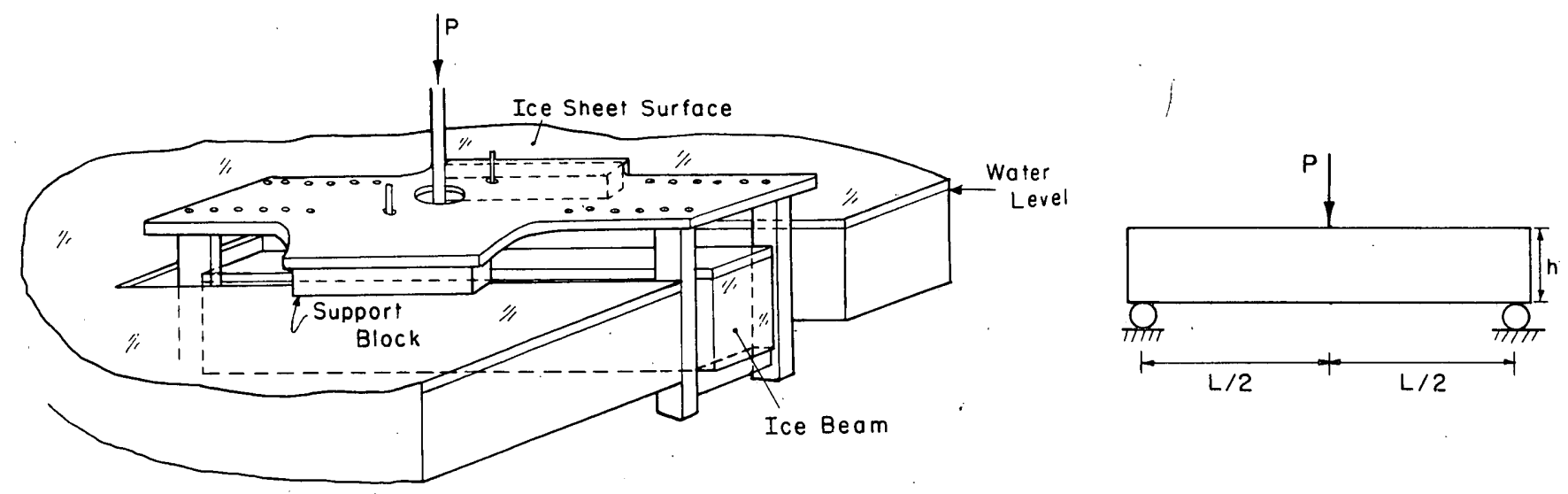

b. In-situ simple beam test.
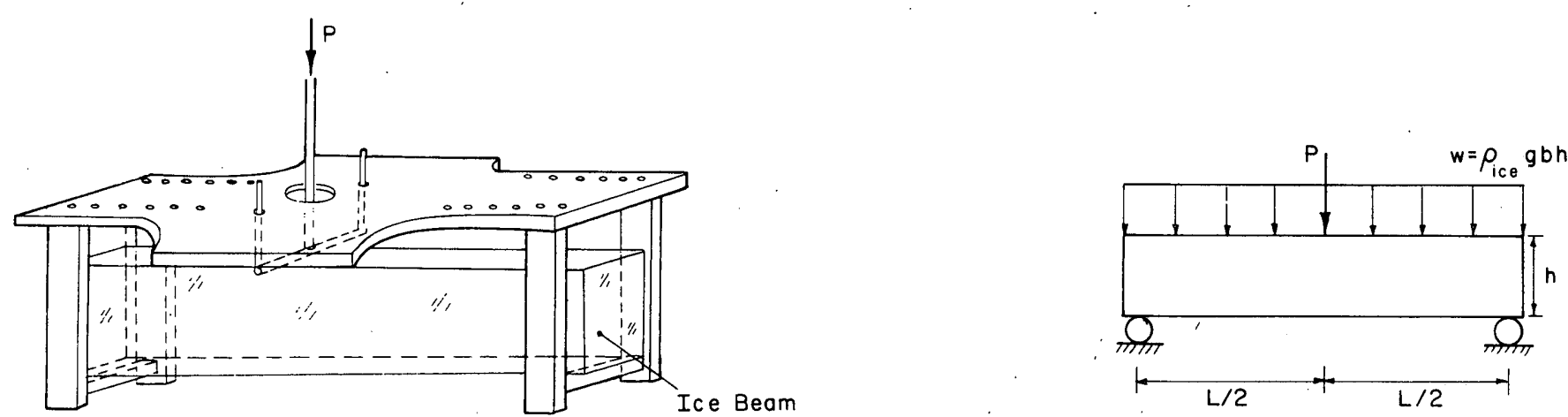

c. Out-of-water simple beam test.

Figure 1. Test set-up and corresponding beam diagrams. 
$-4^{\circ} \mathrm{C}$ to retard ice growth and to help stabilize the ice properties. A more detailed discussion of ice growth techniques for the CRREL test basin is provided by Hirayama (1983).

The resulting ice sheet had a two-layered, columnar structure similar to most ice sheets grown using this technique (Hirayama 1983, Gow 1984, Timco 1984). Typically the top layer consisted of fine-grained columnar crystals and was thinner and stronger than the bottom layer. The bottom layer was made up of coarse-grained columnar crystals. Ice crystals ranged in size from 1 to 2 $\mathrm{mm}$ in the top layer and were $5 \mathrm{~mm}$ or more in the bottom layer for a typical 7-cm-thick ice sheet.

\section{Beam test methods}

A total of 23 series of beam tests were systematically conducted on 10 different ice sheets ranging in thickness from about $35 \mathrm{~mm}$ to $110 \mathrm{~mm}$. Each series consisted of four consecutive beam tests and took about an hour to complete. The first test in a series was the CBI, followed by the SBI and the SBO. An additional CBI test was done as the fourth test in the series to document any change in the ice strength over the time span of testing. Beams were failed in top-tension (i.e. the top surface of the ice sheet was in tension) and bottom-tension modes. Initially the load actuator speed was varied from 6 to $12 \mathrm{~mm} / \mathrm{s}$, but no effect on the strength values was observed so the rate was $\mathrm{kept}$ at $12 \mathrm{~mm} / \mathrm{s}$. This speed resulted in a time-to-failure of $0.5-1 \mathrm{~s}$.

The CBI tests were conducted using guidelines recommended by the IAHR Working Group on Testing Methods in Ice (Schwarz et al. 1981) and Timco (1981). The beam geometry (Fig. 1) was described in terms of the ratio of length $L$ to thickness $h$ (5:1 to $7: 1$ for my beams, as recommended by Timco for model ice) and the ratio of width $B$ to thickness (1:1 to $2: 1$ ). This geometry has been shown to minimize buoyancy effects (Tatinclaux and Hirayama 1982). Cantilever beams were handsawn from the ice sheet (Fig. 1a). Each beam was broken in downward or upward bending by using a motordriven actuator to apply load $P$ to the tip of the beam. A load cell mounted on the actuator was used to monitor the maximum applied force $P_{\max }$ at failure. After each beam was broken, $L$ and $B$ were measured with a ruler to an accuracy of $1 \mathrm{~mm}$, and $h$ was measured with a vernier caliper to an accuracy of $0.1 \mathrm{~mm}$. The flexural strength $\sigma_{\mathrm{f}}$ was then calculated using simple elastic beam theory from

$$
\sigma_{\mathrm{f}}=\frac{6 P_{\max } L}{B h^{2}} .
$$

Typically five beams were tested in rapid succession and the results averaged.

The SB tests were conducted using the same IAHR guidelines as for the CBI tests with but a few exceptions. Beams were cut out of the ice sheet and loaded at three equidistant points in the SB test apparatus (Fig. 1b,c). After the beams were cut out of the ice sheet and tested, I discovered that about a third of the beams had $L / h$ ratios less than $5: 1$.

The SB test apparatus, designed for laboratory tests, has two roller supports and a slot at the top to ensure proper placement of the loading point at the midspan of the beam. The length between the roller supports is adjustable to accommodate various beam lengths. The beam lengths were generally 250,330 and $450 \mathrm{~mm}$, depending on the ice thickness. The same motor-driven actuator used for the CBI tests was used for the SB tests.

For the SBI tests the apparatus was placed in the water and supported in a slot cut in the surrounding ice sheet (Fig. 1b). Wood blocks were wedged between the frame and the ice sheet to provide adequate clearance to just slide the floating beam over the roller supports. After aligning the beam in proper position in the frame, a downward-acting load was applied to the top of the beam at the midspan. To cause bending in the beams so that the fibers at the top ice surface were stressed in tension (toptension tests), the beams were flipped over before placing them in the frame. Similarly, to stress the bottom fibers in tension (bottom-tension tests), the beams were placed right side up in the frame. The flexural strength was calculated using elastic beam theory:

$$
\sigma_{\mathrm{f}}=\frac{3 \cdot P_{\max } L}{2 B h^{2}}
$$

$$
\text { where } \begin{aligned}
P_{\max } & =\text { maximum force at failure } \\
L & =\text { length between the roller supports } \\
B & =\text { ice beam width } \\
h & =\text { thickness of the beam. }
\end{aligned}
$$

Since the beam was tested in the water, the effect of the weight of the beam was cancelled out by buoyancy effects. Several beams were tested in each series and the results averaged in each test.

The SBO tests (Fig. 1c) took place much like the SBI tests, the only difference being that tests were accomplished on a carriage just above the water surface. The beams were removed from the water and then carefully placed and aligned in the frame as quickly as possible. The flexural strength was then calculated from

$$
\sigma_{\mathrm{f}}=\frac{3 P_{\max } L}{2 B h^{2}}+\frac{3 \rho g L^{2}}{4 h}
$$

where $\rho$ is the ice density $\left(920 \mathrm{~kg} / \mathrm{m}^{3}\right)$ and $g$ is acceleration due to gravity. Again, as for the previous beam test methods, several beams were tested and their results averaged. 
Table 1. Flexural strength results from each test series. Each value represents the mean result from 3-5 tests.

\begin{tabular}{|c|c|c|c|c|c|c|c|c|c|c|c|c|c|}
\hline \multirow[b]{3}{*}{$\begin{array}{c}\text { lce } \\
\text { sheet } \\
\text { no. }\end{array}$} & \multirow[b]{3}{*}{$\begin{array}{c}\text { Test } \\
\text { series } \\
\text { no. }\end{array}$} & \multirow[b]{3}{*}{$\begin{array}{c}\text { Tension } \\
\text { side }^{*}\end{array}$} & \multirow[b]{3}{*}{$\begin{array}{c}h \\
(m m)\end{array}$} & \multicolumn{10}{|c|}{ In-situ cantilever beams } \\
\hline & & & & \multicolumn{4}{|c|}{ Initial. } & \multicolumn{4}{|c|}{ Final } & \multicolumn{2}{|c|}{ Average } \\
\hline & & & & $\begin{array}{c}L \\
(\mathrm{~mm})\end{array}$ & $L / h$ & $\begin{array}{c}\sigma_{f} \\
(k P a)\end{array}$ & $\begin{array}{c}\text { Std. } \\
\text { dev. } \\
(k P a)\end{array}$ & $\begin{array}{c}L \\
(m m)\end{array}$ & $L / h$ & $\underset{(k P f a)}{\sigma_{f}}$ & $\begin{array}{c}\text { Std } \\
\text { dev. } \\
(k P a)\end{array}$ & $\underset{(k P a)}{\sigma_{f}}$ & $\begin{array}{c}\text { Std } \\
d e v \\
(k P a)\end{array}$ \\
\hline \multirow[t]{2}{*}{1} & 1 & $\mathrm{~T}$ & 72.1 & 480 & 6.6 & 75.6 & 7.8 & 483 & 6.7 & 82.9 & 5.2 & 79.2 & 7.1 \\
\hline & 2 & $\mathrm{~T}$ & 74.1 & 479 & 6.4 & 51.4 & 2.9 & 443 & 6.1 & 42.9 & 3.5 & 47.1 & 5.4 \\
\hline \multirow[t]{2}{*}{2} & 3 & B & 100.0 & 488 & 4.9 & 48.7 & 5.9 & - & - & - & - & 48.7 & 5.9 \\
\hline & 4 & $\mathrm{~T}$ & 106.0 & 491 & 4.6 & 64.1 & 3.5 & 507 & 4.7 & 68.9 & 2.7 & 65.9 & 3.9 \\
\hline \multirow[t]{2}{*}{3} & 6 & $\mathrm{~T}$ & 44.4 & 271 & 6.1 & 79.7 & 7.1 & 293 & 6.6 & 77.9 & 11.0 & 78.6 & 9.1 \\
\hline & 7 & B & 45.0 & 267 & 5.9 & 34.7 & 2.2 & 272 & 6.1 & 28.1 & 1.2 & 31.4 & 3.8 \\
\hline \multirow[t]{3}{*}{4} & 8 & B & 51.8 & 282 & 5.5 & 31.2 & 4.4 & - & - & - & - & 31.2 & 4.4 \\
\hline & 9 & $\mathrm{~T}$ & 53.1 & 257 & 4.9 & 35.6 & 9.9 & 249 & 4.7 & 34.8 & 7.9 & 35.2 & 8.4 \\
\hline & 10 & . B & 51.9 & 266 & 5.1 & 33.9 & 7.6 & - & - & - & - & 33.9 & 7.6 \\
\hline 5 & 11 & B & 51.7 & 284 & 5.6 & 28.7 & 2.5 & 287 & 5.5 & 29.3 & 5.3 & 29.0 & 3.7 \\
\hline 6 & 12 & $\mathrm{~T}$ & 57.1 & 394 & 6.9 & 33.9 & 2.0 & 363 & 6.2 & 36.9 & 6.3 & 35.4 & 4.6 \\
\hline 7 & 13 & $\mathrm{~T}$ & 102.0 & 477 & 4.6 & 104.0 & 6.9 & 426 & 4.2 & 84.8 & 5.3 & 94.3 & 11.6 \\
\hline \multirow[t]{2}{*}{8} & 14 & $\mathrm{~T}$ & 83.5 & 440 & 5.3 & 91.9 & 5.5 & 454 & 5.5 & 80.4 & 5.1 & 86.1 & 7.8 \\
\hline & 15 & B & 84.8 & 452 & 5.3 & 50.0 & 2.3 & 395 & 4.6 & 53.0 & 2.3 & 51.5 & 2.6 \\
\hline \multirow[t]{3}{*}{9} & 16 & $\mathrm{~T}$ & 33.2 & 189 & 5.8 & 54.2 & 5.8 & 175 & 5.2 & 54.4 & $3: 3$ & 54.3 & 4.4 \\
\hline & 17 & B & 35.5 & 185 & 5.3 & 38.4 & 1.0 & 177 & 4.9 & 41.8 & 4.1 & 40.1 & 3.3 \\
\hline & 18 & $\mathrm{~T}$ & 35.7 & 199 & 5.6 & 42.9 & 3.3 & 181 & 5.1 & 43.9 & 3.3 & 43.4 & 3.2 \\
\hline \multirow[t]{5}{*}{10} & 19 & $\mathrm{~T}$ & 45.0 & 254 & 5.7 & 62.9 & 5.4 & 234 & 5.2 & 48.1 & 2.5 & 56.3 & 8.8 \\
\hline & 20 & $\mathrm{~T}$ & 46.6 & 254 & 5.5 & 42.2 & 3.1 & 240 & 5.1 & 45.6 & 2.9 & 43.9 & 3.3 \\
\hline & 21 & $\mathrm{~T}$ & 47.8 & 267 & 5.6 & 45.2 & 4.0 & 246 & 5.1 & 41.0 & 2.8 & 42.6 & 3.7 \\
\hline & 22 & $\mathrm{~T}$ & 48.4 & 273 & 5.6 & 49.8 & 3.5 & 261 & 5.4 & 50.4 & 5.1 & 50.1 & 4.2 \\
\hline & 23 & $\mathrm{~T}$ & 47.9 & 280 & 5.8 & 54.8 & 2.6 & 278 & 5.8 & 74.5 & 5.1 & 67.1 & 11.0 \\
\hline
\end{tabular}

Three-point simple beams

\begin{tabular}{|c|c|c|c|c|c|c|c|c|c|c|c|c|}
\hline \multirow[t]{2}{*}{1} & 1 & $\mathrm{~T}$ & 72.1 & 450 & 6.2 & 47.1 & 6.2 & 450 & 6.3 & 48.7 & 4.7 & \\
\hline & 2 & $T$ & 74.1 & 250 & 3.3 & 41.6 & 6.6 & 250 & 3.4 & 44.4 & 3.4 & \\
\hline \multirow[t]{2}{*}{2} & 3 & B & 100.0 & 250 & 2.5 & 50.1 & 2.0 & 250 & 2.5 & 67.4 & 2.9 & \\
\hline & 4 & $T$ & 106.0 & 250 & 2.3 & 71.8 & 5.9 & 250 & 2.4 & 61.6 & 10.0 & \\
\hline \multirow[t]{2}{*}{3} & 6 & $\mathrm{~T}$ & 44.4 & 250 & 5.6 & 69.6 & 7.0 & 250 & 5.6 & 65.2 & 4.3 & , \\
\hline & 7 & B & 45.0 & 250 & 5.6 & 23.9 & · $\quad 3.8$ & 250 & 5.5 & 27.9 & 2.0 & \\
\hline \multirow[t]{3}{*}{4} & 8 & B & 51.8 & 250 & 4.8 & 26.7 & 2.7 & 250 & 4.9 & 37.3 & 1.9 & \\
\hline & 9 & $\mathrm{~T}$ & 53.1 & 250 & 4.6 & 39.7 & 1.9 & 250 & 4.6 & 33.3 & 6.2 & \\
\hline & 10 & B & 51.9 & 250 & 4.8 & 34.2 & 5.1 & 250 & 4.9 & 32.7 & 4.1 & \\
\hline 5 & 11 & B & 51.7 & 250 & 4.8 & 22.2 & 1.3 & 250 & 4.8 & 28.3 & 0.9 & \\
\hline 6 & 12 & $\mathrm{~T}$ & .57 .1 & 250 & 4.4 & 26.1 & 2.1 & 250 & 4.4 & 34.2 & 2.4 & \\
\hline 7 & 13 & $T$ & 102.0 & 330 & 3.3 & 103.0 & 5.2 & 330 & 3.3 & 125.0 & 5.3 & \\
\hline \multirow[t]{2}{*}{8} & 14 & $T$ & 83.5 & 330 & 3.9 & 97.7 & 7.8 & 330 & 3.9 & 108.0 & 4.4 & \\
\hline & 15 & B & 84.8 & 330 & 4.0 & 52.7 & 5.2 & 330 & 3.9 & 62.1 & 5.3 & \\
\hline \multirow[t]{3}{*}{9} & 16 & $T$ & 33.2 & 250 & 7.4 & 54.6 & 10.0 & 250 & 7.6 & 56.1 & 1.8 & \\
\hline & 17 & B & 35.5 & 250 & 7.1 & 16.1 & 1.2 & 250 & 7.1 & 21.3 & 0.9 & \\
\hline & 18 & $\mathrm{~T}$ & 35.7 & 250 & 7.0 & 29.0 & 3.6 & 250 & 7.0 & 34.3 & 2.5 & \\
\hline \multirow[t]{5}{*}{10} & 19 & $\mathrm{~T}$ & 45.0 & 250 & 5.5 & 43.6 & 2.2 & 250 & 5.6 & 42.3 & 3.2 & \\
\hline & 20 & $\mathrm{~T}$ & 46.6 & 250 & 5.4 & 36.5 & 2.7 & 250 & 5.4 & 20.5 & 1.1 & \\
\hline & 21 & $\mathrm{~T}$ & 47.8 & 250 & 5.2 & 32.8 & 3.2 & 250 & 5.2 & 31.8 & 2.0 & \\
\hline & 22 & $\mathrm{~T}$ & 48.4 & 250 & 5.2 & 41.1 & 2.5 & 250 & 5.2 & 42.2 & 3.9 & \\
\hline & 23 & $\mathrm{~T}$ & 47.9 & 250 & 5.2 & 62.3 & 7.5 & 250 & 5.2 & 59.5 & 2.3 & \\
\hline
\end{tabular}

$* \mathrm{~T}=$ Top surface in tension.

$\mathrm{B}=$ Bottom surface in tension. 


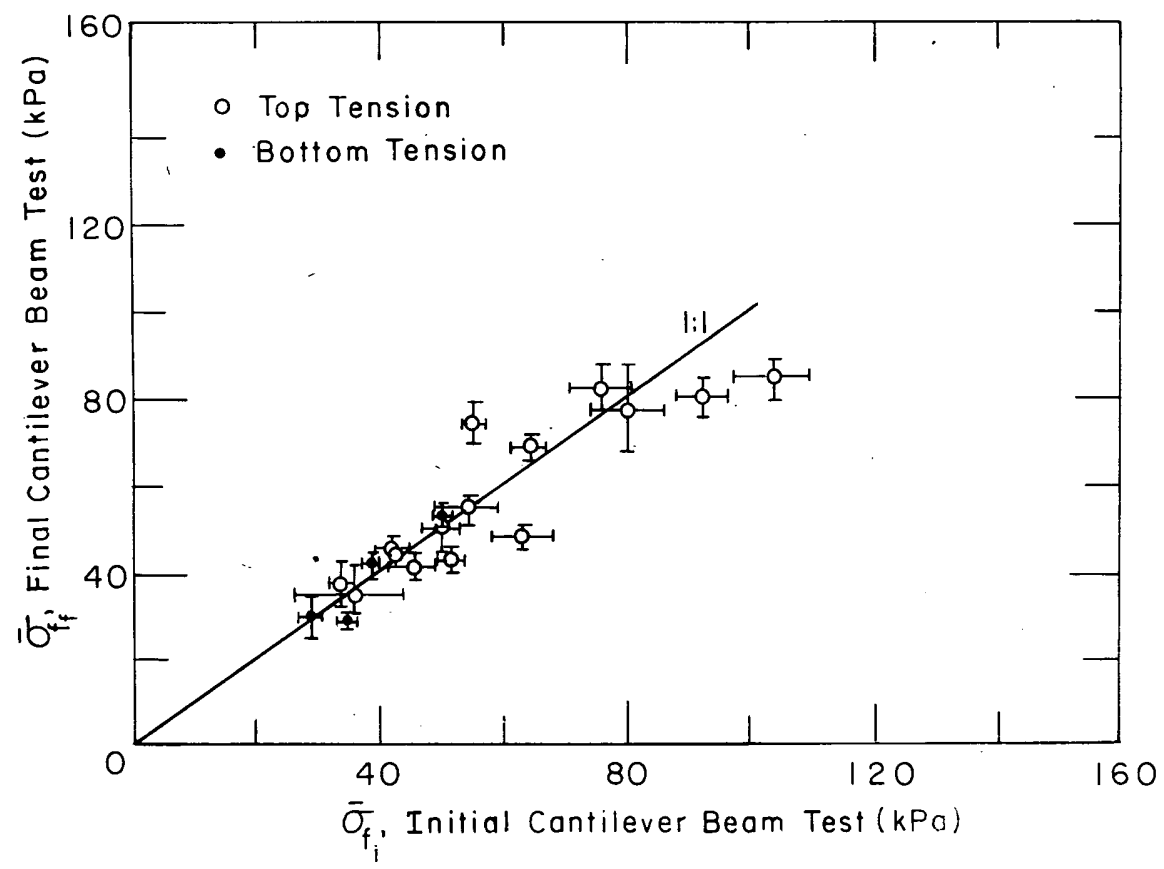

Figure 2. Flexural strength values obtained from initial and final in-situ cantilever beam tests for each series. Each data point represents the mean value of several bean samples, and the corresponding standard deviations are indicated by the bars at each point.

\section{RESULTS}

\section{Comparison of cantilever beam tests}

The values of $\sigma_{f}$ from the initial and final cantilever beam tests in a test series (Table 1), for both top- and bottom-tension modes, are shown in Figure 2. These data indicate good one-to-one correspondence between the $\mathrm{CBI}$ tests. Using a linear regression analysis, the equation of the best-fit line was found to be

$$
\sigma_{\mathrm{f}_{\mathrm{f}}}=0.83\left(\sigma_{\mathrm{f}_{\mathrm{i}}}\right)+8.4
$$

with $91 \%$ correlation $\left(r^{2}=0.82\right)$. Although the slope of this line suggests that the ice sheet strength was reduced slightly over the time it took to run a test series, this change may be considered negligible since the variation coefficient of each data point is $10-15 \%$. This indicates that a slope of 1 and an intercept of 0 (i.e., no change in strength) can reasonably be assumed. Thus, the ice sheet's mechanical properties were essentially stable for the duration of each test series. Both top- and bottomtension test results show this behavior.

\section{Comparison between simple beam tests}

A plot of the results from the SBI and SBO tests (Fig. 3) indicates excellent one-to-one correspondence between the two test methods. Regression analysis re- vealed a correlation coefficientof $95 \%\left(r^{2}=0.90\right)$ for straight-line fit. It appears, then, that there is no significant difference in $\sigma_{\mathrm{f}}$ results from using either test method. However, the $\sigma_{\mathrm{f}}$ values ranged from 20 to $100 \mathrm{kPa}$, and this conclusion may only be valid within this range. This conclusion holds true when the top surface of the ice sheet was in tension. Analysis of the few bottom tension tests, however, shows a slightly higher-slope (1.21) for the best-fit line. These results indicate that the brine drainage resulting from the removal of the ice beam does not significantly alter the structural integrity of the ice and therefore its flexural strength.

\section{Comparison between simple beam and cantilever beam tests}

A comparison of $\sigma_{f}$ values from each simple beam test with the average $\sigma_{\mathrm{f}}$ value from the initial and final cantilever beam tests is shown in Figure 4. The plotted values of $\sigma_{\mathrm{f}}$ (for both top- and bottom-tension modes) indicate a good one-to-one correlation. Clearly there is more scatter in Figure 4 than in Figures 2 or 3. Most of the scatter seen here is the result of combining the data from Figures 2 and 3; the small amount of scatter seen in these figures is amplified in Figure 4. Some of the scatter may also be due to prestressing of the beams, which unavoidably occurred when handling the fragile ice beams. This was especially true for the out-of-water beam tests. The correlations here are not as strong as for the comparison of the simple beam methods (Fig. 3); the 


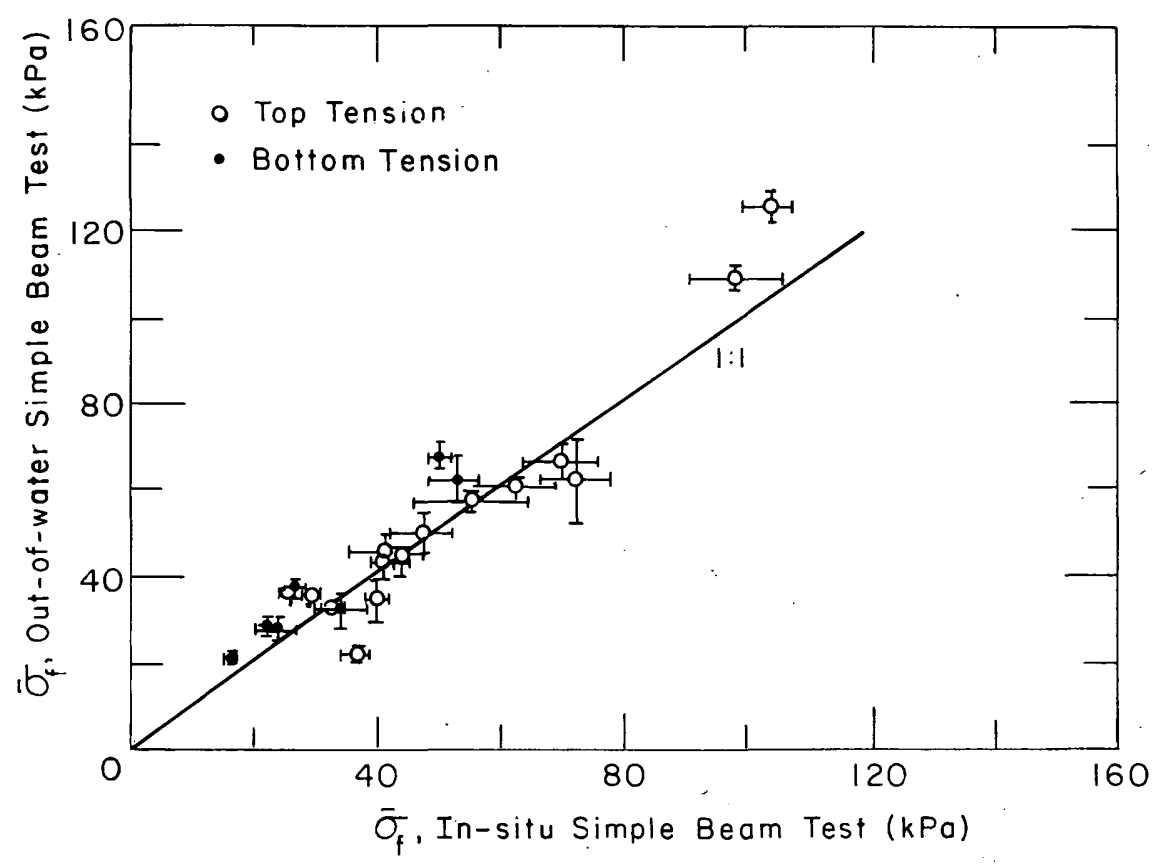

Figure 3. Effect of ice beam placement on flexural strength results from the threepoint simple beam test method.

correlation coefficient was found to be slightly less, $90 \%$. Ice test results, however, typically show $10-15 \%$ variations even under very controlled conditions. Thus, these data indicate that there is little difference in $\sigma_{f}$ when obtained with SB or CBI test techniques either in situ or out of the water.

Previous results in freshwater ice (e.g. Gow et al. 1978) show that significant stress concentrations at the root of a cantilever beam result in a much lower flexural strength value than would be obtained from simple beam tests. Conversely, previously published results for sea ice (Frankenstein 1968, Vaudrey 1978) show no difference in flexural strength values from either test method. Schwarz and Weeks (1977) pointed out that, in sea ice, the stress concentrations in the cantilever beam may be relieved through the plastic flow. Because urea ice (used

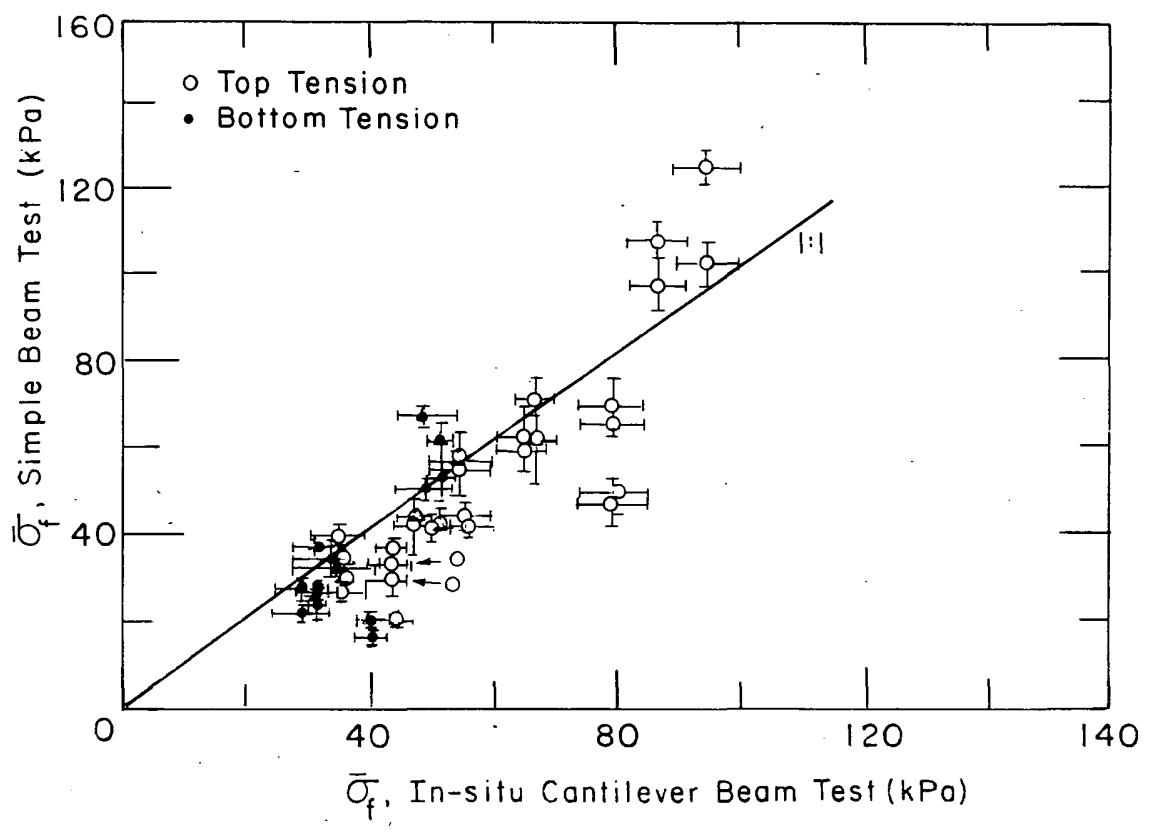

Figure 4. Effect of test method on flexural strength. 


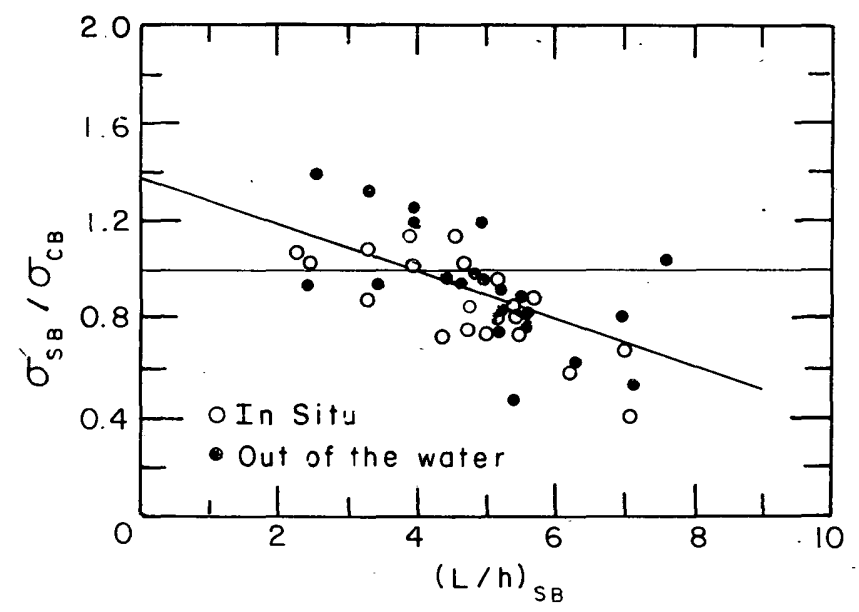

Figure 5. Effect of beam length-to-thickness ratios of the simple beam tests on the relative difference between beam test methods for all the data.

in this study) exhibits similar plastic flow behavior, the effect of the stress concentrations in the cantilever beam on the flexural strength are probably minimal. Thus the flexural strength values as measured using the CBI test or the SB test should be the same for urea ice as confirmed by my results (Fig. 4). These results also confirm similar findings published by Timco (1985) for the urea model ice at the NRCC ice tank.

\section{Effect of $L / h$}

As mentioned previously, about one-fourth of the SB tests were inadvertently conducted using $L / h$ ratios of less than 4 . These low $L / h$ ratios were caused by accidentally failing to adjust the position of the roller supports on the SB apparatus to accommodate thick $(h>80 \mathrm{~mm})$ beam specimens for six test series. The $(L / h)_{\mathrm{SB}}$ ratio ranged from approximately 2 to 7 for the simple beam tests, while $(L / h)_{\mathrm{CB}}$ ranged from 4.5 to 7 for $\mathrm{CBI}$ tests.

The effect of $(L / h)_{\mathrm{SB}}$ on the $\sigma_{\mathrm{SB}} / \sigma_{\mathrm{CB}}$ strength ratio is illustrated in Figure 5. This plot includes all the test series for both in-situ and out-of-water simple beam tests; each point represents the mean value of several beam tests conducted in rapid succession. (The standard deviations were omitted from the plot for clarity.) Since the abscissa contains $L / h$ values from the simple beam test results, Figure 5 shows the effect of varying beam geometry for the simple beams only. Linear regression analysis of these data indicates a definite decreasing trend of the strength ratio $\sigma_{\mathrm{SB}} / \sigma_{\mathrm{CB}}$ with increasing $(L / h)_{\mathrm{SB}}$, even for $L / h$ in the 5-7 range.

The equation for the best-fit curve in Figure 5 was determined to be

$$
\sigma_{\mathrm{SB}} / \sigma_{\mathrm{CB}}=1.38-0.096(L / h)_{\mathrm{SB}} .
$$

Based on this regression equation, then, the value of
$(L / h)_{\mathrm{SB}}$ that best corresponds to a strength ratio $\sigma_{\mathrm{SB}} / \sigma_{\mathrm{CB}}$ of unity is $(L / h)_{\mathrm{SB}}=4$. Allowing $10 \%$ deviation in either direction for the ratio $\sigma_{\mathrm{SB}} / \sigma_{\mathrm{CB}}$, which is well within acceptable limits for ice testing, one can expect to be reasonably confident that the ratio $\sigma_{\mathrm{SB}} / \sigma_{\mathrm{CB}}$ is unity for $(L / h)_{\mathrm{SB}}$ values of 3-5.

It is possible that the effect of $(L / h)_{\mathrm{SB}}$ on the strength ratio in Figure 5 could be due to variations in $\sigma_{\mathrm{CB}}$ with $(L /$ $h)_{\mathrm{CB}}$. To confirm that $\sigma_{\mathrm{SB}}$ is the effect and not $\sigma_{\mathrm{CB}}, \mathrm{I}$ plotted a subset of the data where a narrow range of $(L /$ $h)_{\mathrm{CB}}$ was present. In Figure 6, data are plotted using only those points for which $(L / h)_{\mathrm{CB}}$ is restricted to the narrow range of 4.5-5.5, out of the full range of 4.5-7. Linear regression analysis reveals the equation of the best-fit curve to be

$$
\sigma_{\mathrm{SB}} / \sigma_{\mathrm{CB}}=1.6-0.145(L / h)_{\mathrm{SB}} .
$$

Although the best-fit curve in Figure 6 has a slightly -stéeper negative slope than the curve in Figure 5, the general trend of this data subset is much the same as that for the entire data set seen in Figure 5. Based on the above regression equation for the data subset, the strength ratio is unity for $(L / h)_{\mathrm{SB}}=4.1$, which is nearly the same result obtained for the entire data set, thus confirming that there is no appreciable effect due to the geometric variations in the $\mathrm{CBI}$ tests.

The effect of $(L / h)_{\mathrm{SB}}$ on the strength ratio between insitu and out-of-water simple beam tests was also checked. The ratio $\sigma_{\mathrm{SBO}} / \sigma_{\mathrm{SBI}}$ was plotted against $(L / h)_{\mathrm{SB}}($ Fig. 7). This shows an average ratio close to unity, indicating that $(L / h)_{\mathrm{SB}}$ affects these two test methods identically. Note that $(L / h)_{\mathrm{SB}}$ was identical for the SBO and SBI tests within each series.

These tests have shown that $\sigma_{f}$ may be more sensitive to $L / h$ than previously thought. The effect of $L / h$ both 


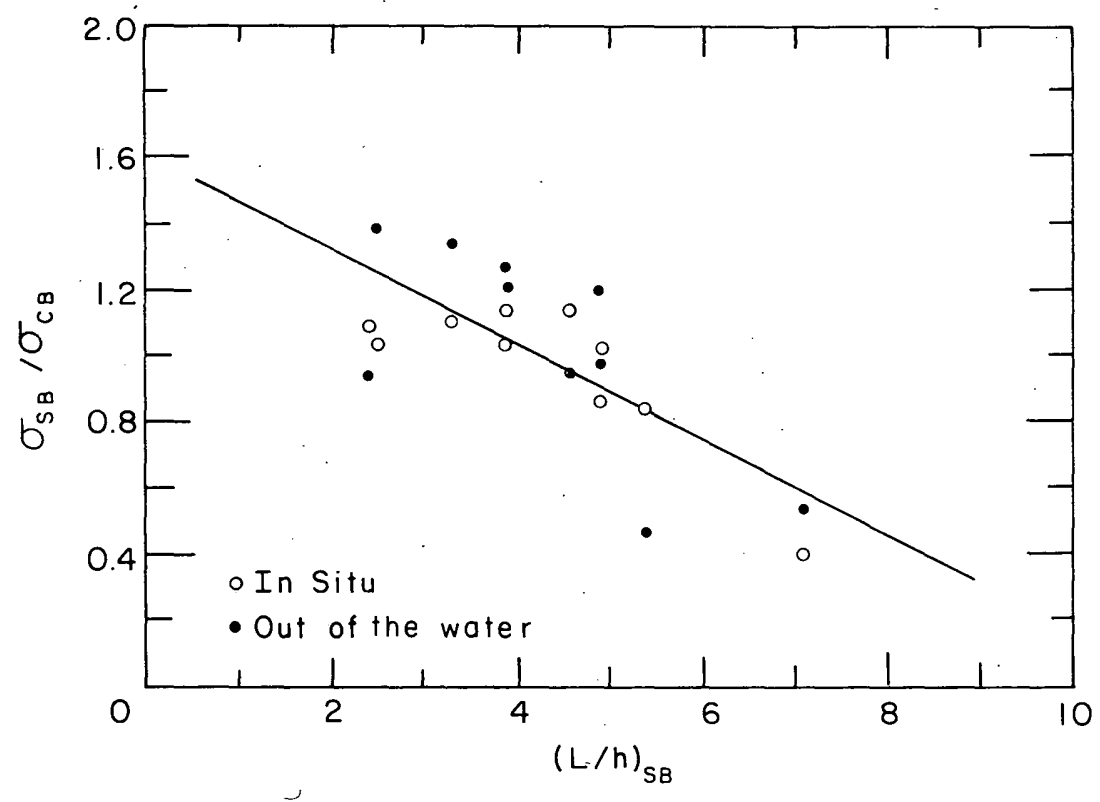

Figure 6. Effect of beam length-to-thickness ratios of the simple beam tests on the relative difference between beam test methods for the data corresponding to cantilever beam tests in which $(\mathrm{L} / \mathrm{h})_{C B}=4.5$ to 5.5 .

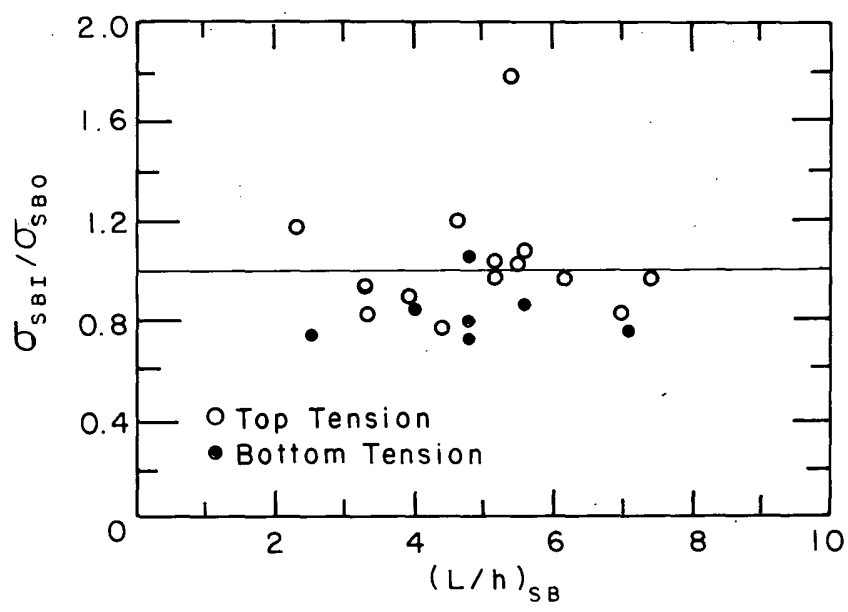

Figure 7. Effect of beam length-to-thickness ratios on the relative difference in flexural strength values obtained from the in-situ and out-of-water simple beam tests.

inside and outside the range 5-7 needs further investigation. Based on my analysis of the effects of beam geometry on strength results, I recommend that $(L / h)_{\mathrm{SB}}=4$ be used in SB tests to get the same results als from $\mathrm{CBI}$ tests for urea model ice.

\section{SUMMARY AND CONCLUSIONS}

A total of ten urea ice sheets ranging in thicknesses from 35 to $110 \mathrm{~mm}$ were tested for flexural strength using three beam test methods. Ice strength was deter- mined by loading the ice beams to failure in flexure using various loading configurations. These configurations included the current standard methods using in-situ cantilever beams and both in-situ and out-of-water threepoint simple beams. For flexural strength values of between 20 and $100 \mathrm{kPa}$, little practical difference in $\sigma$ was found between any of the beam test methods. Based on laboratory observations and analysis, the following conclusions were drawn from this study:

- The ice sheet remained stable with respect to $\sigma_{\text {, }}$ over the hour or so it took to conduct al test series, when the ambient temperature was $-4^{\circ} \mathrm{C}$. 
- No difference in $\sigma_{\mathrm{f}}$ in the range of $20-100 \mathrm{kPa}$ was observed for the three-point loaded simple beam tests, whether the beam was tested in situ or out of the water using a three-point beam loading apparatus.

- Little practical difference was found between threepoint simple beam test results and in-situ cantilever beam test results. This is in agreement with previously published results (Timco 1985).

- Values for $\sigma_{f}$ from the three-point simple beam tests were observed to increase with decreasing $L / h$ for ratios between 2 and 7 .

- For urea model ice, a beam geometry of $L / h=4$ should be used for three-point loaded simple beam tests to obtain the same results as for in-situ cantilever beam tests.

\section{LITERATURE CITED}

Frankenstein, G.E. (1968) Strength of ice sheets. National Research Council of Canada, Associate Committee on Geotechnical Research, Laval University, Quebec City, Quebec, Technical Memorandum No. 92, p. 79-87.

Gow, A.J., H.T. Ueda and J.A. Ricard (1978) Flexural strength of ice on temperate lakes: Comparative tests of large cantilever and simply supported beams. USA Cold Regions Research and Engineering Laboratory, CRREL Report 78-9.

Gow, A.J. (1984) Crystalline structure of urea ice sheets used in modeling experiments in the CRREL test basin. USA Cold Regions Research and Engineering Laboratory, CRREL Report 84-24.

Hirayama, K. (1983) Properties of urea-doped ice in the
CRREL test basin. USA Cold Regions Research and Engineering Laboratory, CRREL Report 83-8.

Schwarz, J. and W.F. Weeks (1977) Engineering properties of sea ice.Journal of Glaciology, 19(81):499-531. Schwarz, J., R. Frederking, V. Gavrillo, I.G. Petrov, K. Hirayama, M. Mellor, P. Tryde and K.D. Vaudrey (1981) Standardized testing methods for measuring mechanical properties of ice. Prepared by the Working Group on Standardized Testing Methods in Ice, IAHR Section on Ice Problems. Journal of Cold Regions Science and Technology, 4: 245-253.

Svec, O.J. and R.M.W. Frederking (1981) Cantilever beam tests in an ice cover: Influence of plate effects at the root. Journal of Cold Regions Science and Technology, 4: 93-101.

Tatinclaux, J.C. and K. Hirayama (1982) Determination of the flexural strength and elastic modulus of ice from in situ cantilever beam tests. Journal of Cold Regions Science and Technology, 6: 37-47.

Timco, G.W. (1981) On the test models for model ice. Journal of Cold Regions Science and Technology, 4: 269-274.

Timco, G.W. (1984) Ice forces on structures: Physical modeling techniques. In 2nd IAHR State-of-the-Ait Report on Ice Forces on Structures, IAHR Ice Symposium, Hamburg, vol. 4, chap. 2, p. 117-150.

Timco, G.W. (1985) Flexural strength and fracture toughness of urea model ice. Proceedings of the Conference on Offshore Mechanics and Arctic Engineering, Dallas, Texas, vol. 2, p. 199-208.

Vaudrey, K.D.(1978) Determination of mechanical sea ice properties by large-scale field beam experiments. Proceedings, 4th International Conference on Port and Ocean Engineering Under Arctic Conditions, Memorial University of Newfoundland, vol. 1, p. 529-543. 
Public reporting burden for this collection of information is estimated to average i hour per response, including the time for reviewing instructions, searching existing data sources, gathering and maintaining the data needed, and completing and reviewing the collection of information. Send comments regarding this burden estimate or any other aspect of this collection of information, including suggestion for reducing this burden, to Washington Headquarters Services, Directorate for Information Operations and Reports, 1215 Jefferson Davis Highway, Suite 1204, Arlington, VA 22202-4302, and to the Office of Management and Budget, Paperwork Reduction Project (0704-0188), Washington, DC 20503.

\begin{tabular}{|l|l|l|}
\hline 1. AGENCY USE ONLY (Leave blank) & $\begin{array}{c}\text { 2. REPORT DATE } \\
\text { August } 1990\end{array}$ & 3. REPORT TYPE AND DATES COVERED \\
\hline 4. TITLE AND SURTITLE & Aug
\end{tabular}

4. TITLE AND SUBTITLE

5. FUNDING NUMBERS

A Comparison of Test Methods for Determination of Flexural Strength in Urea Model Ice

6. AUTHORS

CWIS 31723

Sharon L. Borland

7. PERFORMING ORGANIZATION NAME(S) AND ADDRESS(ES)

8. PERFORMING ORGANIZATION REPORT NUMBER

U.S. Army Cold Regions Research and Engineering Laboratory

72 Lyme Road

Hanover, New Hampshire 03755-1290

Special Report 90-28

9. SPONSORING/MONITORING AGENCY NAME(S) AND ADDRESS(ES)

10. SPONSORING/MONITORING

Office of the Chief of Engineers

Washington, DC 20314-1000 AGENCY REPORT NUMBER

11. SUPPLEMENTARY NOTES

12a. DISTRIBUTION/AVAILABILITY STATEMENT

12b. DISTRIBUTION CODE

Approved for public release; distribution is unlimited.

Available from NTIS, Springfield, Virginia 22161

13. ABSTRACT (Maximum 200 words)

Laboratory tests were performed in a basin to compare the flexural strength of urea ice obtained by three different beam test methods. The beam test methods used were the in-situ three-point loaded simple beam test, the out-of-water three-point loaded simple beam test and the in-situ cantilever beam test. There is essentially no difference in flexural strength determined from either of the three-point beam tests, and the flexural strength obtained from either of the three-point beam tests is also approximately equal to the value determined from the in-situ cantilever beam test. A reduction in flexural strength with increases in beam length-to-thickness ratio was observed for portions of the data set.

\begin{tabular}{|c|c|c|c|}
\hline & $\begin{array}{l}\text { 15. NUMBER OF PAGES } \\
15\end{array}$ \\
\hline $\begin{array}{l}\text { 14. SUBJECT TERMS } \\
\text { Cantilever beam test } \\
\text { Flexural strength }\end{array}$ & $\begin{array}{l}\text { Laboratory tests } \\
\text { Model ice }\end{array}$ & $\begin{array}{l}\text { Simple beam test } \\
\text { Urea ice }\end{array}$ & 16. PRICE CODE \\
\hline $\begin{array}{l}\text { 17. SECURITY CLASSIFICATION } \\
\text { OF REPORT }\end{array}$ & $\begin{array}{l}\text { 18. SECURITY CLASSIFICATION } \\
\text { OF THIS PAGE }\end{array}$ & $\begin{array}{l}\text { 19. SECURITY CLASSIFICATION } \\
\text { OF ABSTRACT }\end{array}$ & 20. LIMITATION OF ABSTRACT \\
\hline UNCLASSIFIED & UNCLASSIFIED & UNCLASSIFIED & UL \\
\hline
\end{tabular}

